\title{
Medicolegal Evaluation of Firearm Injuries Pattern (Fatal and Nonfatal) in Qena Governorate, Egypt during the Years 2010 and 2011 (a Retrospective Study)
}

\author{
Zaghloul T. Mohammed, Khaled M. Abdel Aal'1, Ibrahim N. Mohamed², and Ali \\ Elabd H. Mohamed3
}

${ }^{1}$ Department of Forensic Medicine and Clinical Toxicology, Faculty of Medicine, Assiut University, Assiut.
${ }^{2}$ Department of Forensic Medicine and Clinical Toxicology, Faculty of Medicine, Al Azhar University, Cairo.
${ }^{3}$ Qena Medicolegal Department, Ministry of Justice, Qena

Egypt.

\begin{abstract}
This retrospective study was carried out to evaluate and compare the pattern of firearm injuries in Qena Governorate during the years 2010 and 2011 (before and after the 25th January Egyptian revolution) based on examination of medicolegal reports belong to cases of firearm injuries which referred to the Medicolegal Department of Ministry of Justice, in Qena Governorate. Firearm injuries were 356 and 448 cases which represented $38.56 \%$ and $40.7 \%$ of total cases in years 2010 and 2011 respectively. Most of injuries occurred in males which represented $95.5 \%$ and $96 \%$ of total cases and the highest percentage of victims was in the age group 21-30 years which represented $42.41 \%$ and $42.18 \%$ of total cases in years 2010 and 2011 respectively. The highest percentage of cases among regions of the Governorate was in Deshna center which represented 20.2\% and 20.3\% of total cases in years 2010 and 2011 respectively. Most of cases occurred in summer months which represented $30.34 \%$ and $33 \%$ of total cases in years 2010 and 2011 respectively. Long rifled weapons constituted the highest percentage of used weapons which represented $87.4 \%$ and $96.4 \%$ of total cases in years 2010 and 2011 respectively. The most common site for entrance wounds was the extremities which represented $85.67 \%$ and $81.2 \%$ of total cases in years 2010 and 2011 respectively. Most cases were due to perpendicular firing which represented $84.5 \%$ and $88 \%$ of total cases in years 2010 and 2011 respectively. The head and chest injuries constituted the highest percentage of causes of death which represented $42.1 \%$ and $37 \%$ of total cases in year 2010 while they represented $40.7 \%$ and $31.6 \%$ of total cases in year 2011 respectively. Fatal cases represented $5.3 \%$ and $18.1 \%$ of total cases in years 2010 and 2011 respectively while the nonfatal cases represented $94.7 \%$ and $81.9 \%$ of total cases in years 2010 and 2011 respectively. Permanent infirmities occurred in $7.1 \%$ and $8.7 \%$ of nonfatal cases in years 2010 and 2011 respectively. As regard the manner of injuries, homicidal injuries represented $89.6 \%$ and $87.5 \%$, accidental injury represented $8.9 \%$ and $11.8 \%$, suicidal injury represented $1.5 \%$ and $0.7 \%$ of total cases in years 2010 and 2011 respectively. As regard motives of injuries revenge was the commonest motive for injuries which represented $54.7 \%$ and $44.6 \%$ of total cases then dispute in $32.95 \%$ and $41.47 \%$ of total cases in years 2010 and 2011 respectively. This study concluded that the percentage of firearm injuries was increased in year 2011 than year 2010 due to absence of security role and presence of unlicensed weapons. Minimization of firearm injuries necessitates activation of police role, enforcement of law in prevention of possession and trafficking of unlicensed weapons as well as strengthen the active role of conciliation and dispute resolution committees in the community.
\end{abstract}

Keywords Medicolegal, Firearm injuries, Qena Governorate, Egypt

\section{Introduction}

Girearm injuries continue as a major public health 7 problem, contributing significant morbidity, mortality and expense to different communities (Rana et al., 2012). 
The invention of firearm has come as a curse to this world; it has become the most dreaded killing tool used by human being to kill themselves (Patowary, 2005).

The percentage of firearm injuries and deaths varies greatly in different parts of the world and in different regions of the same country according to availability of weapons (Kapusta et al., 2007, Humayun et al., 2009 and Davies et al., 2012).

The United States has far higher rates of firearm deaths-firearm homicides, suicides, and unintentional deaths compared with other high-income countries (Richardson and Hemenway, 2011).

Firearm injuries can result in deaths, disabilities, emotional turmoil, economic coasts, greater utilization of health care system and burden on legal/police services (Narang et al., 2010).

Many factors increase the incidence of firearm injuries such as gun trafficking, illegal supply of guns to criminals, robberies and assaults (Braga et al., 2012).

Physicians necessitate special training for diagnosis, management and prevention of firearm injuries (Dingeldein, 2012). Forensic pathologist also require special training to diagnose type of wound, direction and distance of firing, type of weapon and manner of death (Naik et al ., 2011).

On examining firearm fatalities, the main goal of forensic analysis is to distinguish firearm suicides from homicides and accidents. The location of wound entrance, wound path trajectory and gunshot residues, blood stain pattern analysis of gunshot-related backspatter on hands of the victim can be essential tools not only to determine which hand was holding the firearm, but also to reconstruct the position from which a weapon was fired (Kunz et al., 2013).

Although a lot of articles about firearm injuries and deaths have been published abroad, there is little studies about the magnitude of this problem in different Egyptian Governorates. Therefore, the objective of this work is to evaluate the pattern of fatal and nonfatal firearm injuries in Qena Governorate during the years 2010 and 2011 (before and after the 25th January Egyptian revolution) that examined by Medicolegal Department of Ministry of Justice in Qena. Also to compare the pattern in Qena with that reported in other Egyptian Governorates and other countries.

\section{Subjects and methods}

All cases of firearm injuries (fatal and nonfatal) from 1 January 2010 to 31 December 2011 were retrospectively studied through manual review of all medicolegal reports belong to cases of firearm injuries from the archives of the Medicolegal Department, Ministry of Justice in Qena Governorate. The cases were analyzed for evaluation of various parameters including age, sex, residence of the victims, as well as seasonal variation, sites of the wound, distance, direction, fate and cause of death of injuries. Manner and motives of injuries was determined using information from case histories, first information reports and scene circumstances. Also the type of weapon used in each case was obtained from records of firearm examiners.

\section{Ethical consideration}

This work was done after approval from the ethical committee of Faculty of Medicine, Assiut University. Agreement for perusal of records was obtained from the head office of Medicolegal Department of Ministry of Justice in Qena Governorate. Confidentiality of the medicolegal reports was maintained by keeping the reports anonymous.

\section{Statistical analysis}

The data collected were organized, tabulated, entered into a computer database program using SPSS (Statistical Package for Social Sciences) software version 16. Data was statistically analyzed using Chisquare test was used. Identification of the significance of differences between the years 2010 and 2011 by $p$ value while demonstration of the significance of differences between groups of the same year by $X^{2}$ and $\mathrm{Z}$ values.

\section{Results}

Figure (1) shows percentage of firearm injuries to total cases examined by the medicolegal department in Qena Governorate in the years 2010 and 2011. The cases were 356 and 448 which represented $38.56 \%$ and $40.72 \%$ of total cases during years 2010 and 2011 respectively.

Table (1) and figure (2) show age distribution of victims of firearm injuries (fatal and nonfatal) in Qena Governorate in years 2010 and 2011. There was a highly significant difference between all age groups in each of years 2010 and 2011 ( $P$ value $<=0.01$ ). The highest percentage of cases was in age group 21-30 which represented $42.41 \%$ and $42.17 \%$ of total cases in years 2010 and 2011 respectively followed by the age group 31-40 years which represented $41.85 \%$ and $40.17 \%$ of total cases respectively. There was no significant difference between the years 2010 and 2011 as regard the percentage of each age groups ( $\mathrm{p}$ value $>0.05$ ).

Figure (3) shows sex distribution of victims of firearm injuries (fatal and nonfatal) in Qena Governorate during the years 2010 and 2011. Most of the victims where males who represented $95.5 \%$ and $96 \%$ during the years 2010 and 2011 respectively

Table (2) shows residence distribution of victims of firearm injuries fatal and nonfatal) in Qena Governorate in years 2010 and 2011. There was highly significant difference between all regions of Qena Governorate in each of the years 2010 and 2011 (P value $<0.01$ ) as regard number of cases but there was no significant difference in number of cases of the same region in years 2010 and 2011 ( $\mathrm{P}$ value $>0.05$ ). The highest percentage of firearm injuries was in Deshna rural area which represented $20.2 \%$ and $20.3 \%$ of total cases in years 2010 and 2011 respectively. Then Qena city which represented $14.9 \%$ and $14.5 \%$ of total cases in years 2010 and 2011 respectively followed by and Luxor city which represented $13 \%$ and $11.8 \%$ of total cases in years 2010 and 2011 
respectively.

Table (3) and figure (4) show seasonal variation of firearm (fatal and nonfatal) in Qena Governorate in years 2010 and 2011. There was significant difference between all seasons as regard number of cases in the years 2010 ( $P$ value $<=0.05$ =significant). There was highly significant difference between all seasons as regard number of cases in year 2011 ( $\mathrm{P}$ value $<0.01$ ). There was no significant difference in number of cases of the same season between the two years 2010 and 2011 ( $p$ value $>0.05$ ). The highest percentage of firearm injuries was in summer months which represented $30.34 \%$ and $33 \%$ of total cases in years 2010 and 2011 respectively followed by spring months which represented $26.13 \%$ and $27.46 \%$ of total cases in years 2010 and 2011 respectively.

Table (4) show number of inlet and exit wounds of firearm injuries in Qena Governorate in years 2010 and 2011. There was a highly significant increase in number of cases of multiple inlets than single inlet wound in each of years 2010 and 2011 (P value $<=0.01$ ). Multiple inlets represented $57.6 \%$ and $66 \%$ of total cases in years 2010 and 2011 respectively. There was a highly significant increase in number of cases of presence of exit wound than absence of exits in each of years 2010 and 2011 (P value $<=0.01$ ). Exit wounds were found in $86.70 \%$ and $88.2 \%$ of total cases in years 2010 and 2011 respectively.

Table (5) and figure (5) show types of firearm weapons which used in induction of injuries in Qena Governorate in years 2010 and 2011. There was a highly significant increase in number of long rifled weapons than other types of weapons each of years 2010 and 2011 ( $P$ value $<=0.01$ ). There was a highly significant increase in use of long rifled weapons in year 2011 than year 2010 ( $P$ value $<0.01$ ) and a highly significant decrease in number of short rifled weapons in year 2011 than year 2010 ( $\mathrm{P}$ value $<=0.01$ ). Long rifled weapons were the commonest used weapons which represented $87.4 \%$ and $96.4 \%$ of total cases in years 2010 and 2011 respectively. Then short rifled weapons which represented $11 \%$ and $2.7 \%$ of total cases during the years 2010 and 2011 respectively. Lastly the non-rifled weapons which represented smallest percentage $1.6 \%$ and $0.9 \%$ of total cases in years 2010 and 2011 respectively.

Table (6) shows distance of firing of firearm injuries in Qena Governorate in years 2010 and 2011. There was a highly significant increase in number of cases of far firing than near firing in each of years 2010 and 2011 ( $\mathrm{P}$ value $<=0.01$ ). Distant firing represented the highest percentage $84.5 \%$ and $97.5 \%$ of total cases in years 2010 and 2011 respectively. There was a highly significant increase in number of cases of far firing than near firing in year 2011 than year 2010 (P value $<=0.01$ ) while there was a highly significant decrease in number of cases of near firing than far firing in year 2011 than year 2010 (P value $<=0.01$ )

Table (7) shows the different directions of firing. There were a highly significant increase in cases of perpendicular firing compared to other directions in years 2010 and 2011 (P value $<=0.01$ ). Perpendicular firing represented the highest percentage $84.5 \%$ and $88 \%$ of total cases in years 2010 and 2011 respectively. Oblique firing represented $13.7 \%$ and $9 \%$ of total cases in years 2010 and 2011 respectively.

Table (8) and figure (6) show sites of entrance wounds of firearm projectiles in the victims in Qena Governorate in years 2010 and 2011. The highest percentage occurred in the extremities (upper and lower) which represented $85.67 \%$ and $81.2 \%$ of total cases in years 2010 and 2011 respectively. There were a highly significant increase in number of cases in extremities compared to other sites ( $\mathrm{P}$ value $<=0.01$ ).

Table (9) and figure (7) show motives and manner of firearm injuries in Qena Governorate in years 2010 and 2011. There was a highly significant increase in number of cases of homicidal manner than accidental and suicidal manners in each of years 2010 and 2011 ( $\mathrm{P}$ value $<=0.01)$. Homicidal manner represented $89.6 \%$ and $87.5 \%$, accidental injury represented $8.9 \%$ and $11.8 \%$, suicidal injury represented $1.5 \%$ and $0.7 \%$ of total cases in years 2010 and 2011 respectively. There was a highly significant increase in number of injuries due to revenge than other motives in each of years 2010 and 2011 (P value $<=0.01$ ). Revenge was the commonest motive for injuries which represented $54.7 \%$ and $44.6 \%$ of total cases then dispute which represented $29.2 \%$ and $47.1 \%$ of total cases in years 2010 and 2011 respectively.

Table (10) and figure (8) show fate of firearm injuries (fatal and nonfatal) in Qena Governorate in years 2010 and 2011.The nonfatal cases represented $94.7 \%$ and $81.9 \%$ of total cases in years 2010 and 2011 respectively. There was a highly significant increase in number of fatal cases in year 2011 than year 2010 (P value $<=0.01$ ). Fatal cases represented $5.3 \%$ and $18.1 \%$ of total cases in years 2010 and 2011 respectively. Nonfatal cases represented $94.7 \%$ and $81.9 \%$ of total cases in years 2010 and 2011 respectively. There was a highly significant decrease in number of nonfatal cases in year 2011 than year 2010 ( $\mathrm{P}$ value $<=0.01$ ). Complete cure occurred in $28.8 \%$ and $17.7 \%$ of nonfatal cases in years 2010 and 2011. There was a highly significant decrease in number of complete cure cases in year 2011 than year 2010 ( $\mathrm{P}$ value $<=0.01$ ). Permanent infirmity was occurred in $7.1 \%$ and $8.7 \%$ of nonfatal cases in years 2010 and 2011 respectively. There no significant difference in number of permanent infirmity cases in years 2010 than year 2011(P value $>0.05$ ). Cure with complications (as fractures) represented $59.2 \%$ and $62.5 \%$ of nonfatal cases in years 2010 and 2011 respectively. There was a highly significant increase in number of cases of complete cure with complications in year 2011 than year 2010 (P value $<=0.01)$.

Table (11) shows causes of death in fatal firearm injuries in Qena Governorate in years 2010 and 2011. There was a highly significant increase in number of deaths due to injuries of the brain and chest organs compared to other causes of death in years 2010 and 2011 ( $\mathrm{P}$ value $<=0.01$ ). Laceration of brain and meninges represented $42.1 \%$ and $37 \%$ of total cases in years 2010 and 2011 respectively. There were a 
significant increase in cases of lacerations of the brain and meninges in year 2010 than year 2011 (P value $<=0.05)$. Laceration of heart and lungs represented $31.6 \%$ and $40.7 \%$ of total cases in years 2010 and 2011 respectively. There were a highly significant increase in cases of lacerations of the heart and lungs in year 2011 than year 2010 ( $P$ value $<=0.01)$.

Table (1): Chi-square statistical analysis of age distribution of victims of firearm injuries in Qena Governorate in years 2010 and 2011.

\begin{tabular}{|c|c|c|c|c|c|c|}
\hline \multirow{2}{*}{ Age groups } & \multicolumn{2}{|c|}{2010} & \multicolumn{2}{|c|}{2011} & \multirow{2}{*}{$\mathbf{Z}$} & \multirow{2}{*}{$P$ value } \\
\hline & No. & Percent & No. & Percent & & \\
\hline$<10 \mathrm{Y}$ & 5 & 1.4 & 11 & 2.46 & 0.81 & 0.210 \\
\hline $10-20 \mathrm{Y}$ & 14 & 3.93 & 19 & 4.24 & 0.04 & 0.484 \\
\hline $21-30 \mathrm{Y}$. & 151 & 42.41 & 190 & 42.41 & -0.07 & 0.472 \\
\hline $31-40 \mathrm{Y}$. & 149 & 41.85 & 179 & 39.95 & 0.47 & 0.318 \\
\hline $41-50 \mathrm{Y}$ & 27 & 7.6 & 38 & 8.48 & 0.33 & 0.369 \\
\hline$>51 \mathrm{Y}$ & 10 & 2.81 & 11 & 2.46 & 0.09 & 0.464 \\
\hline Total & 356 & & 448 & & & \\
\hline $\mathrm{X}^{2}$ & \multicolumn{2}{|c|}{504.03} & \multicolumn{2}{|c|}{590.03} & & \\
\hline $\mathrm{P}$ value & \multicolumn{2}{|c|}{$0.0003 * *$} & \multicolumn{2}{|c|}{$0.00003 * *$} & & \\
\hline
\end{tabular}

$P$ value: $>0.05$ non-significant, $\leq 0.05=$ significant, $\leq 0.01$ highly significant.

Table (2): Chi-square statistical analysis of residence distribution of victims of firearm injuries in Qena Governorate in years 2010 and 2011.

\begin{tabular}{|c|c|c|c|c|c|c|}
\hline \multirow{2}{*}{ Region } & \multicolumn{2}{|c|}{2010} & \multicolumn{2}{|c|}{2011} & \multirow{2}{*}{$\mathbf{Z}$} & \multirow{2}{*}{$P$ value } \\
\hline & No. & Percent & No. & Percent & & \\
\hline Deshna & 72 & 20.2 & 91 & 20.3 & -0.06 & 0.477 \\
\hline Nag Hamady & 35 & 9.8 & 41 & 9.2 & 0.21 & 0.418 \\
\hline Qena city & 53 & 14.9 & 65 & 14.5 & 0.05 & 0.479 \\
\hline Luxor & 46 & 13 & 53 & 11.8 & 0.36 & 0.359 \\
\hline Armant & 39 & 11 & 44 & 9.8 & 0.41 & 0.341 \\
\hline Abo Tesht & 28 & 7.9 & 34 & 7.6 & 0.01 & 0.494 \\
\hline Ques & 21 & 6 & 28 & 6.3 & 0.06 & 0.476 \\
\hline Farshot & 29 & 8.1 & 41 & 9.1 & 0.38 & 0.353 \\
\hline Isna & 14 & 3.9 & 19 & 4.2 & 0.04 & 0.484 \\
\hline Qeft & 7 & 1.9 & 11 & 2.5 & 0.23 & 0.411 \\
\hline Naqada & 8 & 2.2 & 13 & 2.9 & 0.36 & 0.361 \\
\hline Al Waqf & 4 & 1.1 & 8 & 1.8 & 0.48 & 0.316 \\
\hline Total & 356 & 100 & 448 & 100 & & \\
\hline $\mathrm{X}^{2}$ & \multicolumn{2}{|c|}{173.2} & \multicolumn{2}{|c|}{190.44} & & \\
\hline $\mathrm{P}$ value & \multicolumn{2}{|c|}{$0.00001 * *$} & \multicolumn{2}{|c|}{$0.000002 * *$} & & \\
\hline
\end{tabular}

$P$ value: $>0.05$ non-significant, $\leq 0.05=$ significant, $\leq 0.01$ highly significant.

Table (3): Chi-square statistical analysis of seasonal variation of firearm injuries in Qena Governorate in years 2010 and 2011.

\begin{tabular}{|c|c|c|c|c|c|c|}
\hline \multirow{2}{*}{ Season } & \multicolumn{2}{|c|}{2010} & \multicolumn{2}{|c|}{2011} & \multirow{2}{*}{$\mathbf{Z}$} & \multirow{2}{*}{ P value } \\
\hline & No. & Percent & No. & Percent & & \\
\hline Winter & 72 & 20.22 & 85 & 18.97 & 0.36 & 0.361 \\
\hline Autumn & 83 & 23.31 & 92 & 20.54 & 0.86 & 0.194 \\
\hline Summer & 108 & 30.34 & 148 & 33.03 & 0.74 & 0.229 \\
\hline Spring & 93 & 26.12 & 123 & 27.46 & 0.34 & 0.365 \\
\hline Total & 356 & & 448 & & & \\
\hline $\mathrm{X}^{2}$ & \multicolumn{2}{|c|}{10.53} & \multicolumn{2}{|c|}{30.29} & & \\
\hline P. value & \multicolumn{2}{|c|}{$0.014^{*}$} & \multicolumn{2}{|c|}{$0.000001 * *$} & & \\
\hline
\end{tabular}

$P$ value: $>0.05$ non-significant, $\leq 0.05=$ significant, $\leq 0.01$ highly significant . 
Table (4): Chi-square statistical analysis of number of inlets and exits wounds of firearm injuries in Qena Governorate in years 2010 and 2011.

\begin{tabular}{|c|c|c|c|c|c|c|}
\hline \multirow{2}{*}{ Type of wound } & \multicolumn{2}{|c|}{2010} & \multicolumn{2}{|c|}{2011} & \multirow{2}{*}{$\mathbf{Z}$} & \multirow{2}{*}{$P$ value } \\
\hline & No. & Percent & No. & Percent & & \\
\hline \multicolumn{7}{|l|}{ Inlet wound } \\
\hline 1. $\quad$ Single & 151 & 42.4 & 153 & 34 & 2.33 & $0.009 * *$ \\
\hline 2. $\quad$ Multiple & 205 & 57.6 & 270 & 66 & 0.70 & 0.243 \\
\hline $\mathrm{X}^{2}$ & \multicolumn{2}{|c|}{16.45} & \multicolumn{2}{|c|}{91.75} & & \\
\hline P. value & \multicolumn{2}{|c|}{$0.000005 * *$} & \multicolumn{2}{|c|}{$0.000001 * *$} & & \\
\hline \multicolumn{7}{|l|}{ Exit wound } \\
\hline 1. Present & 309 & 86.7 & 395 & 88.2 & 0.48 & 0.316 \\
\hline 2. Absent & 47 & 11.30 & 53 & 11.8 & 0.48 & 0.316 \\
\hline$X^{2}$ & \multicolumn{2}{|c|}{404.91} & \multicolumn{2}{|c|}{522.99} & & \\
\hline P. value & \multicolumn{2}{|c|}{$0.000005 * *$} & \multicolumn{2}{|c|}{$0.000003 * *$} & & \\
\hline
\end{tabular}

$P$ value: $>0.05$ non-significant, $\leq 0.05=$ significant, $\leq 0.01$ highly significant.

Table (5): Chi-square statistical analysis of types of weapons used in infliction of firearm injuries in Qena Governorate in years 2010 and 2011.

\begin{tabular}{|l|c|c|c|c|c|c|}
\hline \multirow{2}{*}{ Type of weapon } & \multicolumn{2}{|c|}{$\mathbf{2 0 1 0}$} & \multicolumn{2}{c|}{$\mathbf{2 0 1 1}$} & \multirow{2}{*}{ Z } & \multirow{2}{*}{ P value } \\
\cline { 2 - 6 } & No. & Percent & No. & Percent & \\
\hline Long rifled & 311 & 87.36 & 432 & 96.4 & 4.69 & $0.000001^{* *}$ \\
\hline Short rifled & 39 & 10.96 & 12 & 2.7 & 4.64 & $0.000002^{* *}$ \\
\hline Non rifled & 6 & 1.68 & 4 & 0.9 & 0.69 & 0.246 \\
\hline Total & \multicolumn{2}{|c|}{356} & 448 & & & \\
\hline$X^{2}$ & \multicolumn{2}{|c|}{708.31} & \multicolumn{2}{|c|}{$0.000005^{* *}$} & & \\
\hline P. value & \multicolumn{2}{|c|}{$0.00004^{* *}$} &
\end{tabular}

$P$ value: $>0.05$ non-significant, $\leq 0.05=$ significant, $\leq 0.01$ highly significant.

Table (6): Chi-square statistical analysis of distance of firing of firearm injuries in Qena Governorate in years 2010 and 2011.

\begin{tabular}{|c|c|c|c|c|c|c|}
\hline \multirow{2}{*}{ Distance of firing } & \multicolumn{2}{|c|}{2010} & \multicolumn{2}{|c|}{2011} & \multirow{2}{*}{$\mathbf{Z}$} & \multirow{2}{*}{$P$ value } \\
\hline & No. & Percent & No. & Percent & & \\
\hline Near & 55 & 15.5 & 11 & 2.5 & 6.54 & $0.000001 * *$ \\
\hline Far & 301 & 84.5 & 437 & 97.5 & 6.54 & $0.000001 * *$ \\
\hline Total & 356 & 100 & 448 & 100 & & \\
\hline $\mathrm{X}^{2}$ & \multicolumn{2}{|c|}{338.98} & \multicolumn{2}{|c|}{808.64} & & \\
\hline P. value & \multicolumn{2}{|c|}{$0.00002 * *$} & \multicolumn{2}{|c|}{$0.000003 * *$} & & \\
\hline
\end{tabular}

$P$ value: $>0.05$ non-significant, $\leq 0.05=$ significant, $\leq 0.01$ highly significant.

Table (7): Chi-square statistical analysis of direction of firing of firearm injuries in Qena Governorate in years 2010 and 2011.

\begin{tabular}{|l|c|c|c|c|c|c|}
\hline \multirow{2}{*}{ Direction of firing } & \multicolumn{2}{c|}{$\mathbf{2 0 1 0}$} & \multicolumn{2}{c|}{$\mathbf{2 0 1 1}$ Z } & \multirow{2}{*}{ P value } \\
\cline { 2 - 7 } & No. & Percent & No. & Percent & & 0.088 \\
\hline Perpendicular & 301 & 84.5 & 395 & 88 & 1.39 & $0.025^{*}$ \\
\hline Oblique & 49 & 13.7 & 41 & 9 & 1.95 & 0.240 \\
\hline From above downward & 6 & 1.8 & 12 & 3 & & \\
\hline Total & 356 & 100 & 448 & 100 & & \\
\hline$X^{2}$ & \multicolumn{2}{|c|}{640.46} & \multicolumn{2}{|c|}{907.33} & & \\
\hline P. value & \multicolumn{2}{|c|}{$0.000003 * *$} & $0.000004 * *$ & & \\
\hline
\end{tabular}

$P$ value: $>0.05$ non-significant, $\leq 0.05=$ significant, $\leq 0.01$ highly significant. 
Table (8): Chi-square statistical analysis of sites of entrance wounds of firearm injuries in the victims in Qena Governorate in years 2010 and 2011.

\begin{tabular}{|c|c|c|c|c|c|c|}
\hline \multirow{2}{*}{ Sites } & \multicolumn{2}{|c|}{2010} & \multicolumn{2}{|c|}{2011} & \multirow{2}{*}{$\mathbf{Z}$} & \multirow{2}{*}{$P$ value } \\
\hline & No. & Percent & No. & Percent & & \\
\hline Head & 11 & 3 & 31 & 6.9 & 2.26 & $0.011^{*}$ \\
\hline Chest & 14 & 3.9 & 37 & 8.3 & 2.35 & $0.009 * *$ \\
\hline Abdomen & 26 & 7.3 & 16 & 3.6 & 2.20 & $0.013^{*}$ \\
\hline Limbs & 305 & 85.8 & 364 & 81.2 & 1.57 & 0.057 \\
\hline Total & 356 & 100 & 448 & 100 & & \\
\hline $\mathrm{X}^{2}$ & \multicolumn{2}{|c|}{937.78} & \multicolumn{2}{|c|}{1008.99} & & \\
\hline P. value & \multicolumn{2}{|c|}{$0.000004 * *$} & \multicolumn{2}{|c|}{$0.000004 * *$} & & \\
\hline
\end{tabular}

$P$ value: $>0.05$ non-significant, $\leq 0.05=$ significant, $\leq 0.01$ highly significant .

Table (9): Chi-square statistical analysis of motives and manner of firearm injuries in Qena Governorate in years 2010 and 2011.

\begin{tabular}{|c|c|c|c|c|c|c|c|}
\hline \multirow{2}{*}{ Manner } & \multirow{2}{*}{ Motives } & \multicolumn{2}{|c|}{2010} & \multicolumn{2}{|c|}{2011} & \multirow[b]{2}{*}{$\mathbf{Z}$} & \multirow{2}{*}{$P$ value } \\
\hline & & No. & Percent & No. & Percent & & \\
\hline \multirow{7}{*}{ Homicidal } & Revenge & 195 & 54.7 & 200 & 44.6 & 2.78 & $0.002 * *$ \\
\hline & Dispute & 104 & 29.2 & 181 & 40.4 & 3.22 & $0.0006^{* *}$ \\
\hline & Brawl & 14 & 3.93 & 6 & 1.33 & 2.12 & $0.017^{*}$ \\
\hline & Robbery & 4 & 1.1 & 2 & 0.45 & 0.70 & 0.243 \\
\hline & Cashing criminals & 2 & 0.56 & 3 & 0.67 & -0.26 & 0.398 \\
\hline & $\mathrm{X}^{2}$ & \multicolumn{2}{|c|}{547.52} & \multicolumn{2}{|c|}{650.14} & & \\
\hline & P. value & \multicolumn{2}{|c|}{$0.000003 * *$} & \multicolumn{2}{|c|}{$0.000003 * *$} & & \\
\hline \multirow{4}{*}{ Accidental } & Random shooting in streets/festivals & 7 & 1.97 & 12 & 2.68 & 0.43 & 0.334 \\
\hline & Playing with firearms & 50 & 14 & 25 & 5.58 & 3.98 & $0.00003 * *$ \\
\hline & $\mathrm{X}^{2}$ & \multicolumn{2}{|c|}{35.06} & \multicolumn{2}{|c|}{4.76} & & \\
\hline & P. value & \multicolumn{2}{|c|}{$0.000001 * *$} & \multicolumn{2}{|c|}{$0.029 *$} & & \\
\hline \multirow{4}{*}{ Suicide } & Depression & 4 & 1.1 & 2 & 0.46 & 0.70 & 0.243 \\
\hline & Abuse of drugs & 1 & 0.3 & 1 & 0.23 & -0.55 & 0.291 \\
\hline & $\mathrm{X}^{2}$ & \multicolumn{2}{|c|}{1.64} & \multicolumn{2}{|c|}{0.34} & & \\
\hline & P. value & \multicolumn{2}{|c|}{0.2004} & \multicolumn{2}{|c|}{0.557} & & \\
\hline
\end{tabular}

$P$ value: $>0.05$ non-significant, $\leq 0.05=$ significant, $\leq 0.01$ highly significant .

Table (10): Chi-square statistical analysis of fate of injuries in Qena Governorate in years 2010 and 2011.

\begin{tabular}{|c|c|c|c|c|c|c|}
\hline \multirow{2}{*}{ Fate } & \multicolumn{2}{|c|}{2010} & \multicolumn{2}{|c|}{2011} & \multirow{2}{*}{$\mathbf{Z}$} & \multirow{2}{*}{$P$ value } \\
\hline & No. & Percent & No. & Percent & & \\
\hline Death & 19 & 5.3 & 81 & 18.1 & 5.33 & $0.0001 * *$ \\
\hline \multirow{4}{*}{$\begin{array}{l}\text { Total survived (nonfatal) cases } \\
\text { 1. Complete cure } \\
\text { 2. Cur with permanent infirmity } \\
\text { 3. Cure with complications }\end{array}$} & 337 & $94.7 \%$ & 367 & $81.9 \%$ & 5.33 & $0.0001 * *$ \\
\hline & 97 & 28.8 & 65 & 17.7 & 3.40 & $0.0003 * *$ \\
\hline & 24 & 7.1 & 32 & 8.7 & 0.64 & 0.260 \\
\hline & 216 & 64.1 & 270 & 73.6 & 2.63 & $0.004 * *$ \\
\hline Total cases & 356 & 100 & 448 & 100 & & \\
\hline $\mathrm{X}^{2}$ & \multicolumn{2}{|c|}{380.26} & \multicolumn{2}{|c|}{364.71} & & \\
\hline P. value & \multicolumn{2}{|c|}{$0.000003 * *$} & \multicolumn{2}{|c|}{$0.000003 * *$} & & \\
\hline
\end{tabular}

$P$ value: $>0.05$ non-significant, $\leq 0.05=$ significant, $\leq 0.01$ highly significant.

Table (11): Chi-square statistical analysis of causes of death of fatal firearm injuries in Qena Governorate in years 2010 and 2011.

\begin{tabular}{|c|c|c|c|c|c|c|}
\hline \multirow{2}{*}{ Causes of death } & \multicolumn{2}{|c|}{2010} & \multicolumn{2}{|c|}{2011} & \multirow[t]{2}{*}{$\mathbf{Z}$} & \multirow[t]{2}{*}{ P value } \\
\hline & No. & $\%$ & No. & $\%$ & & \\
\hline Lacerations of brain and meanings & 152 & $42.7 \%$ & 164 & $36.6 \%$ & 1.68 & $0.046^{*}$ \\
\hline Lacerations of heart and lungs & 112 & $31.6 \%$ & 182 & $40.7 \%$ & 2.61 & $0.004 * *$ \\
\hline $\begin{array}{l}\text { Lacerations of abdominal organs } \\
\text { (liver, kidneys, spleen, stomach, viscera) }\end{array}$ & 54 & $15.2 \%$ & 74 & $16.5 \%$ & 0.42 & 0.336 \\
\hline Lacerations of blood vessels and hemorrhage & 19 & $5.3 \%$ & 22 & $5 \%$ & 0.11 & 0.455 \\
\hline Fracture of vertebral column and spinal cord injury & 19 & $5.3 \%$ & 6 & $1.3 \%$ & 3.04 & $0.001 * *$ \\
\hline Total & 356 & & 488 & & & \\
\hline $\mathrm{X}^{2}$ & \multicolumn{2}{|c|}{238.52} & \multicolumn{2}{|c|}{367.62} & & \\
\hline P. value & \multicolumn{2}{|c|}{$0.000002 * *$} & \multicolumn{2}{|c|}{$0.000002 * *$} & & \\
\hline
\end{tabular}

$P$ value: $>0.05$ non-significant, $\leq 0.05=$ significant, $\leq 0.01$ highly significant . 


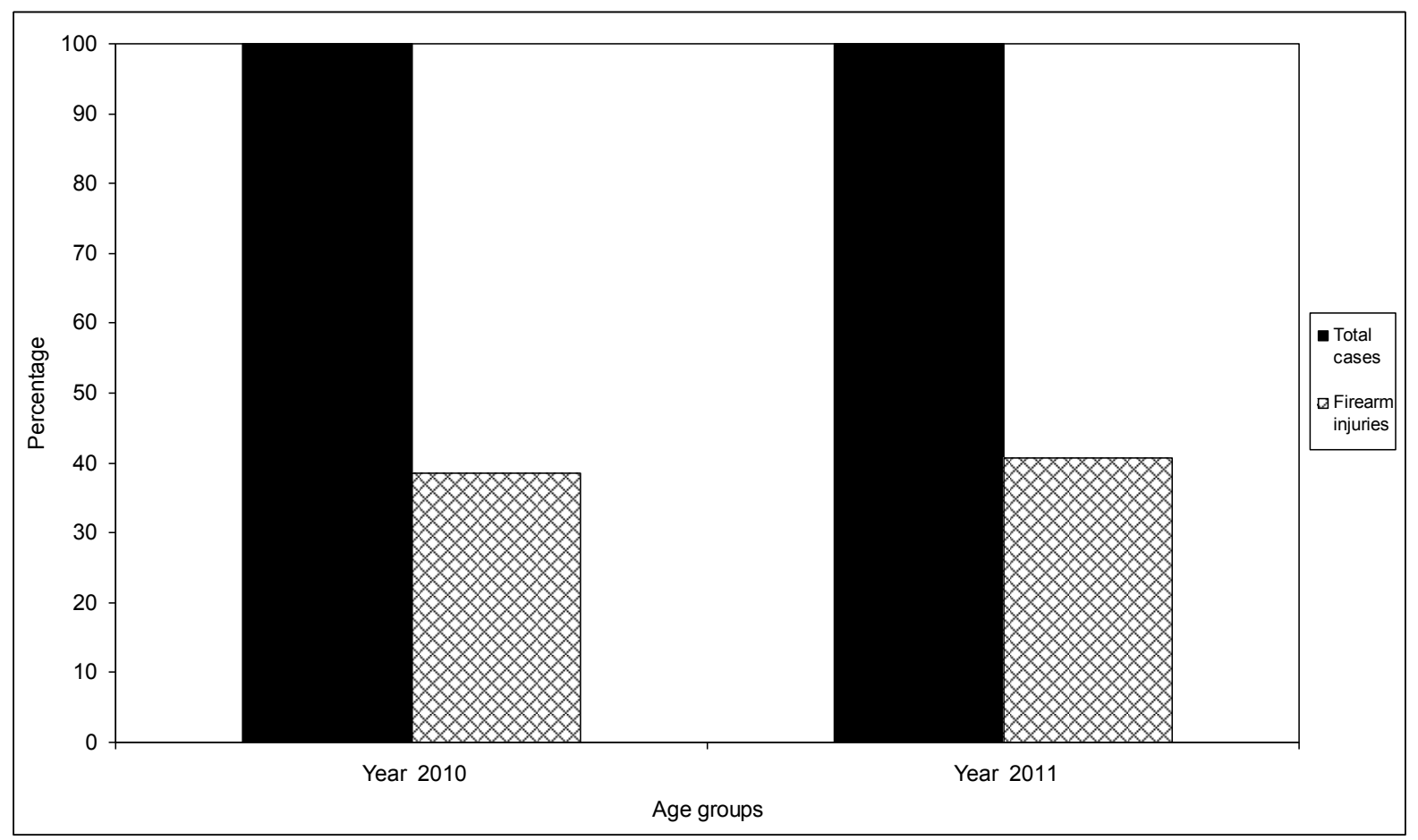

Figure (1): Percentage of firearm injuries to total cases in Qena Governorate in years 2010 and 2011.

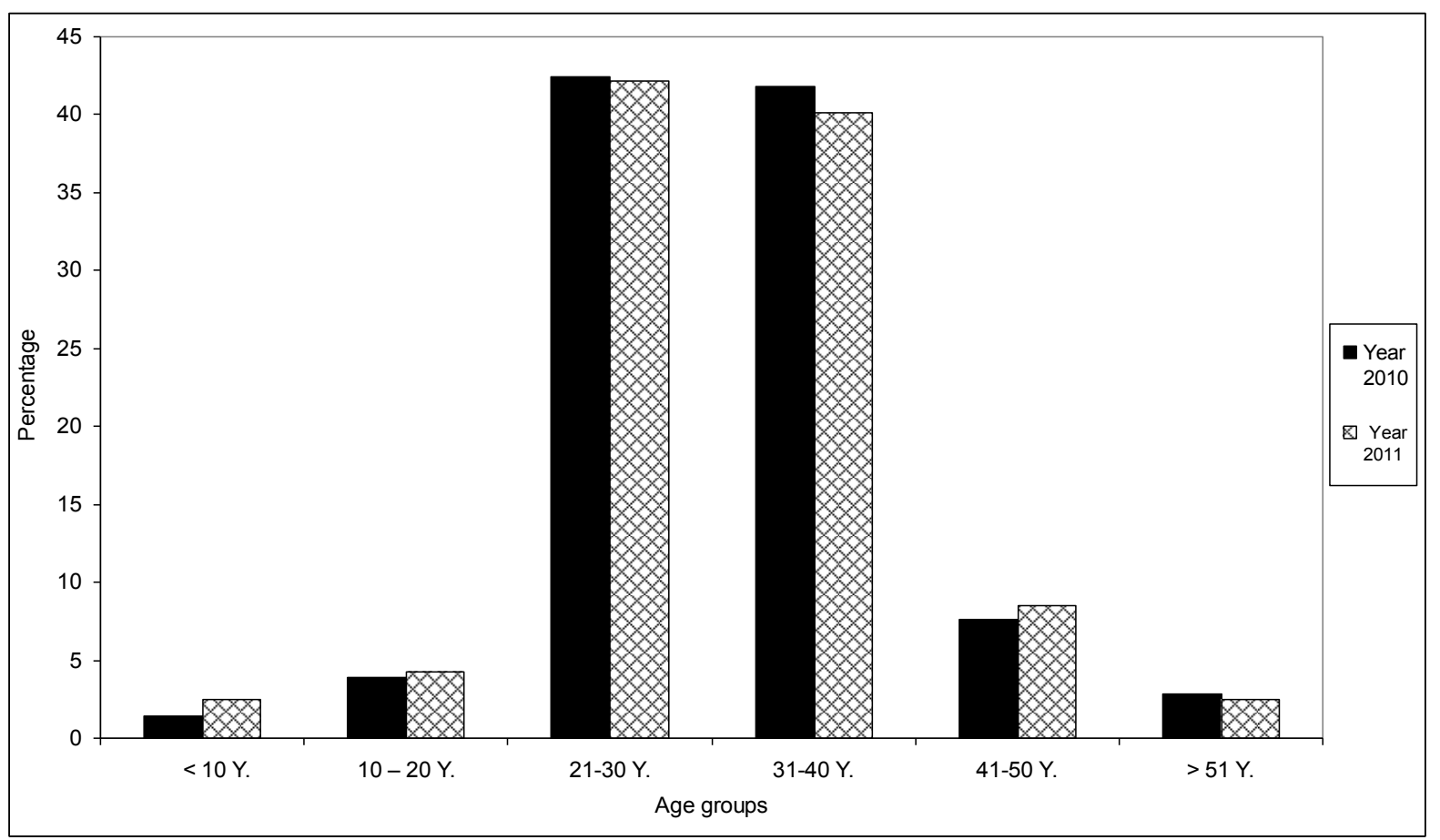

Figure (2): Age distribution of victims of firearm injuries (fatal and nonfatal) in Qena Governorate in years 2010 and 2011. 


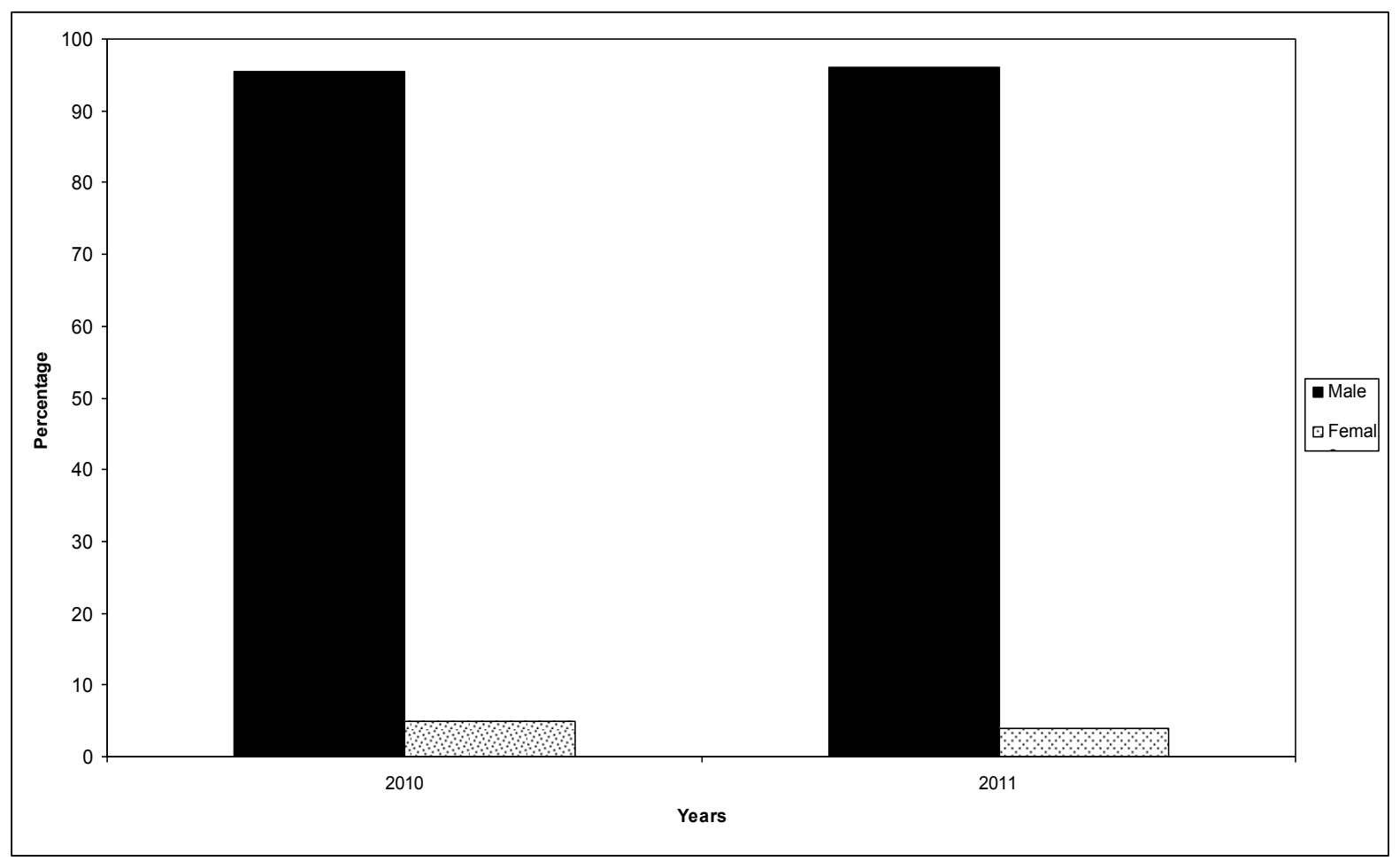

Figure (3): Sex distribution of firearm injuries in Qena Governorate in years 2010 and 2011.

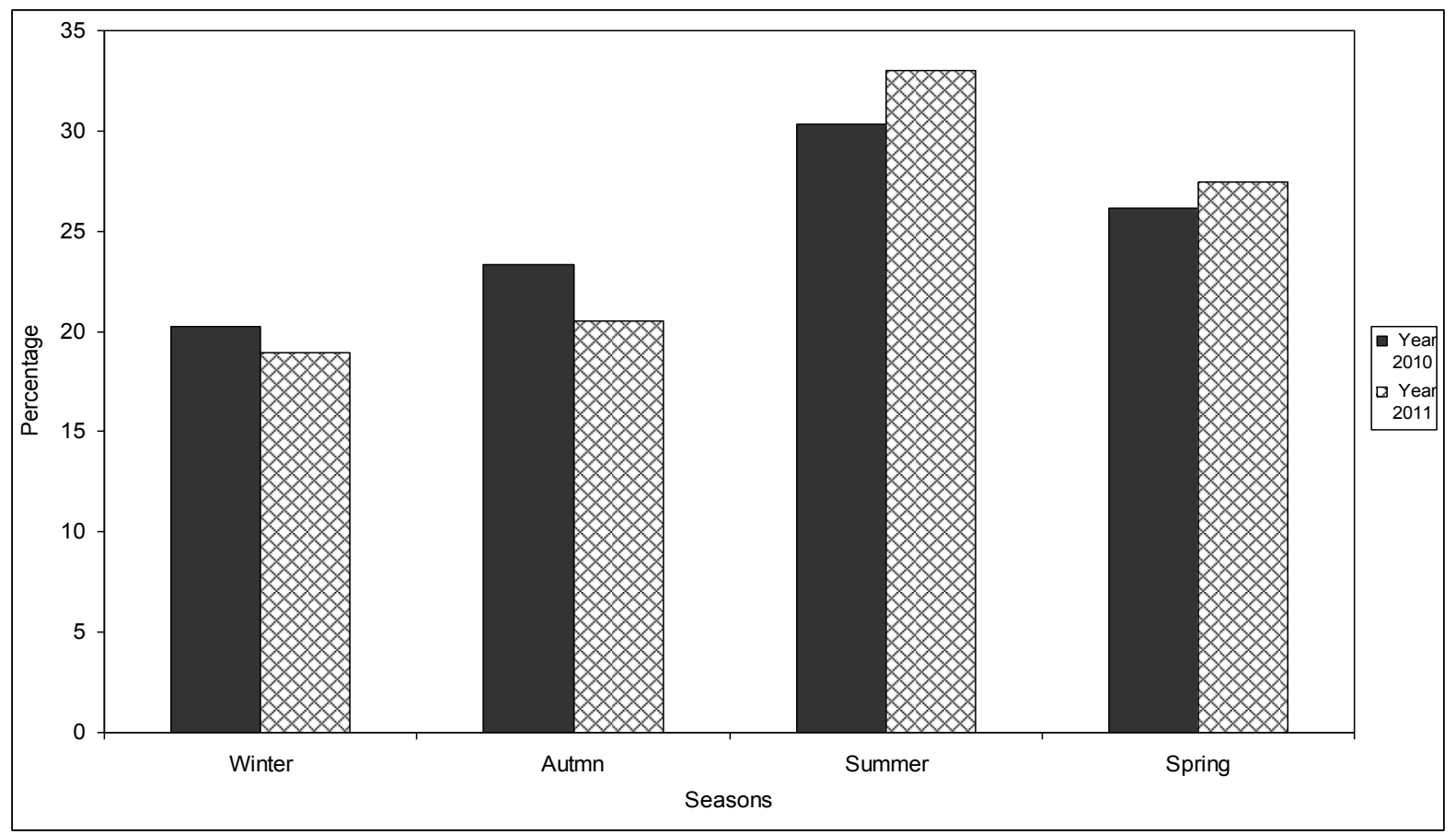

Figure (4): Seasonal variation of firearm injuries in Qena Governorate in years 2010 and 2011. 


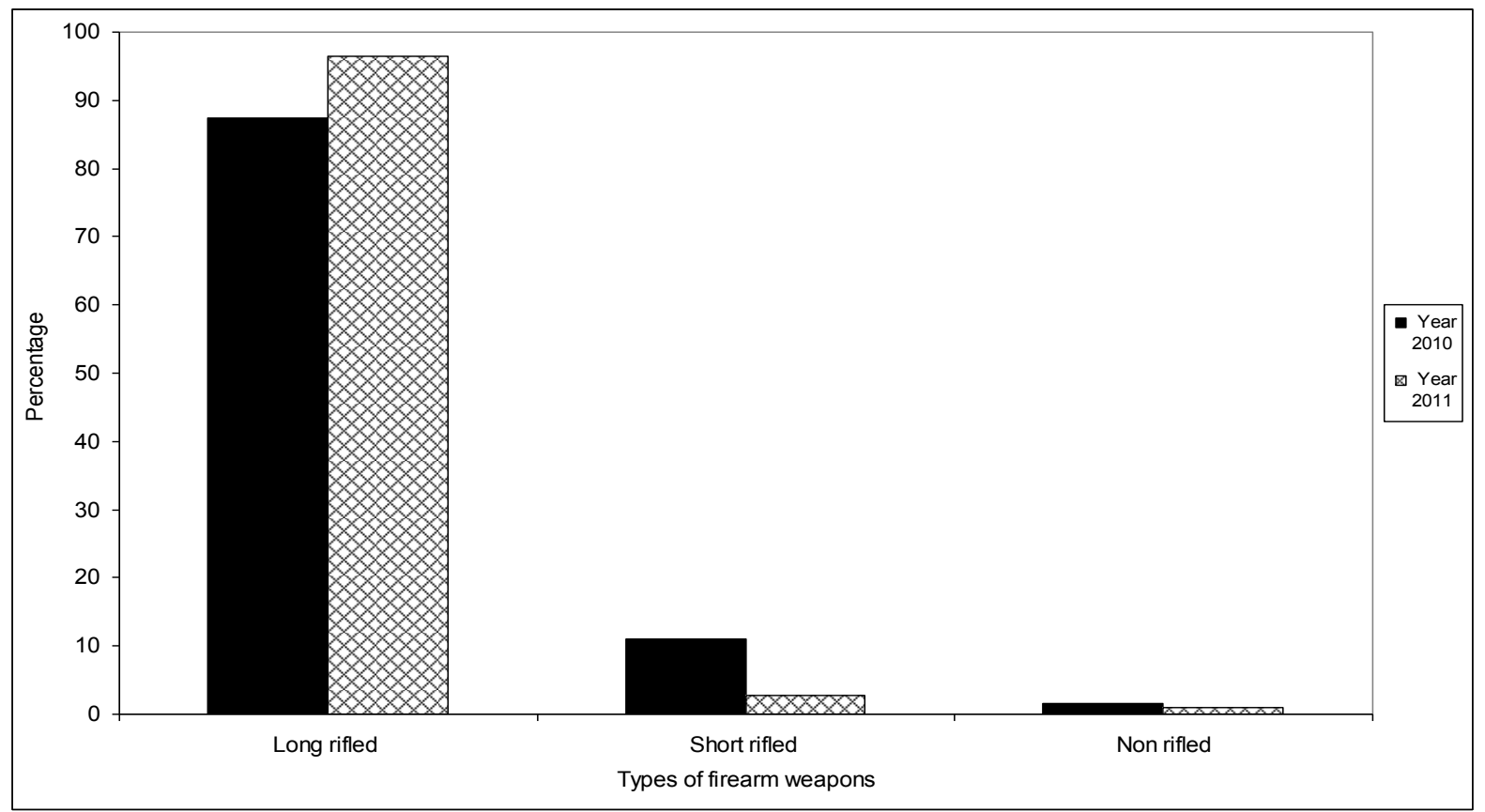

Figure (5): Types of weapons used in firearm injuries in Qena Governorate in years 2010 and 2011.

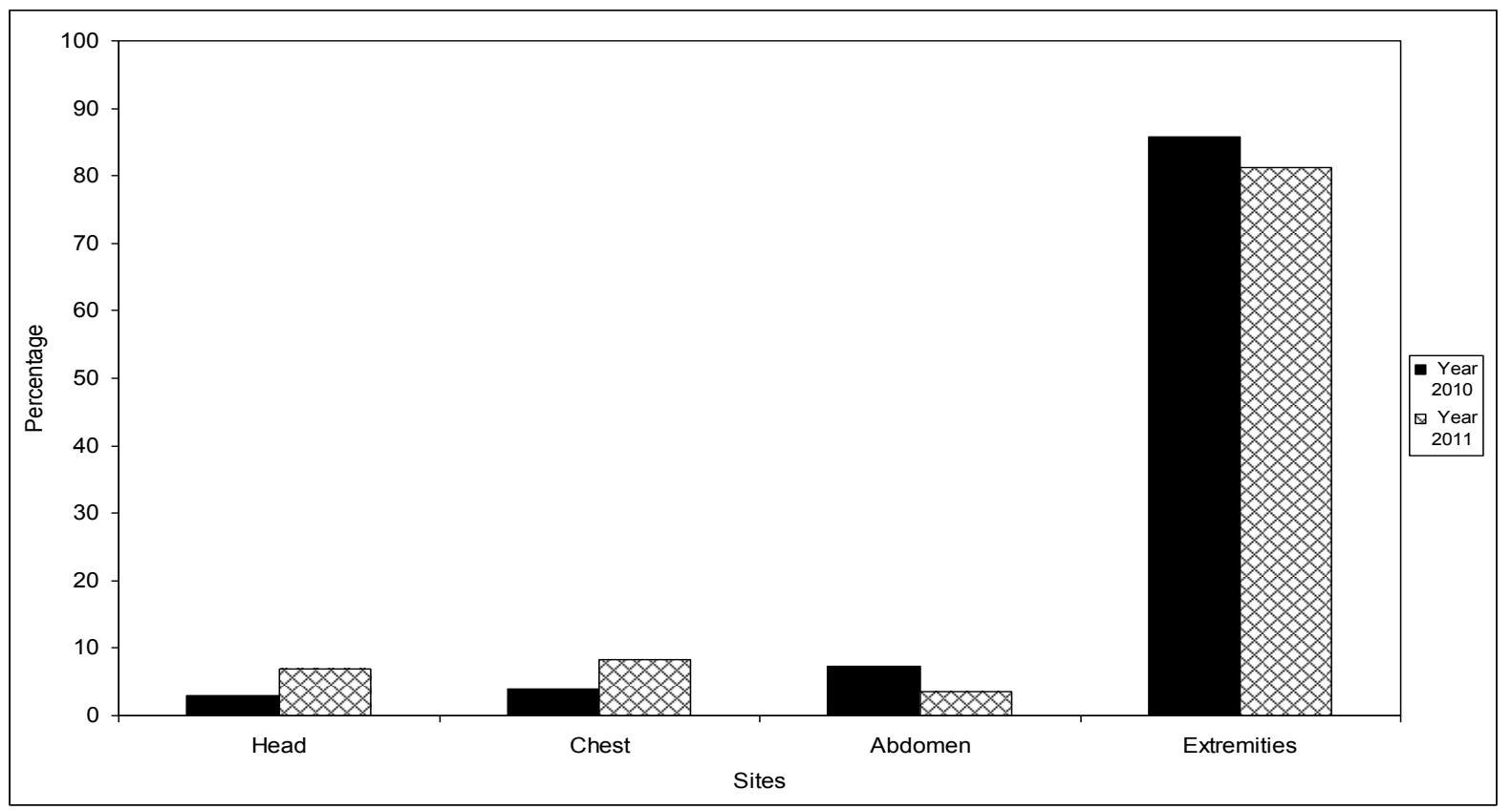

Figure (6): Sites of entrance wounds of firearm projectiles in the victims in Qena Governorate in years 2010 and 2011. 


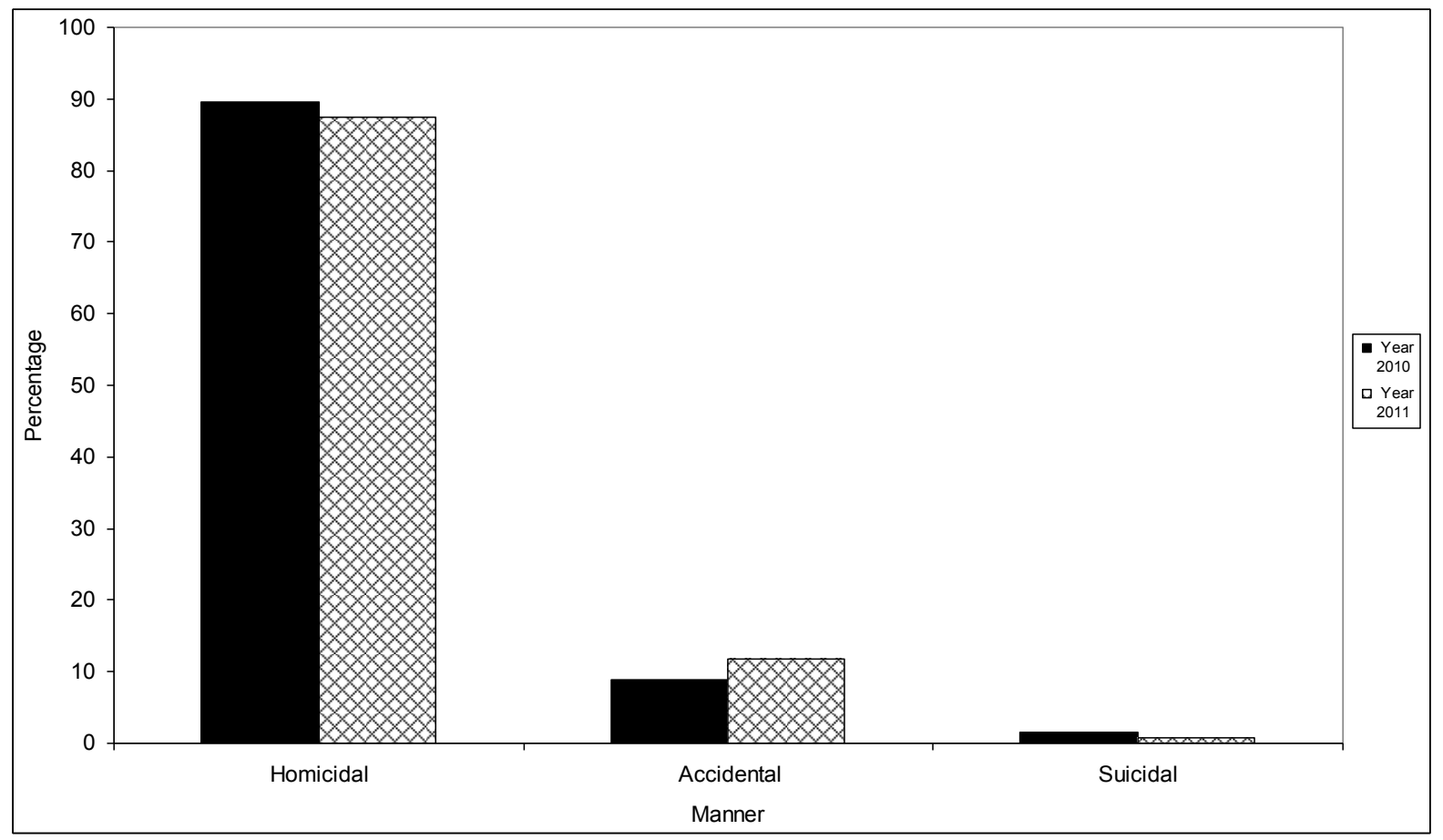

Figure (7): Manner of firearm injuries in Qena Governorate in years 2010 and 2011.

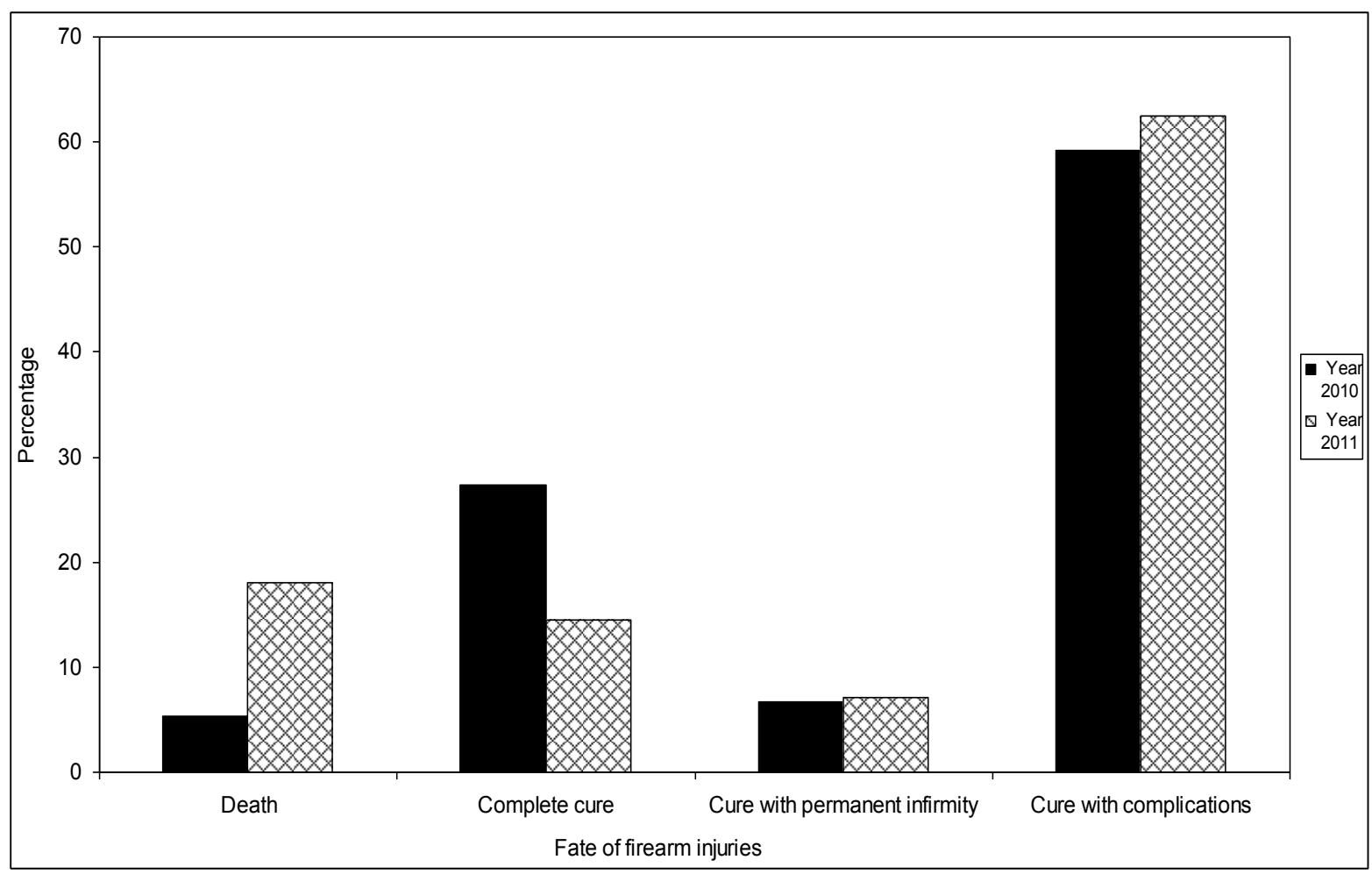

Figure (8): Fate of firearm injuries in Qena Governorate in years 2010 and 2011.

\section{Discussion}

Firearm injuries represent a major public health problem throughout the world resulting in substantial morbidity, mortality and permanent disability, particularly in young individuals (Yacoub et al., 2006).

Firearm injuries and deaths severely affect the health care system and criminal justice (Hargarten, 2002).

The frequency of firearm related deaths appear to be higher in nations where firearm are more readily available, either legally or illegally (Verzeletti et al., 2009).

The present work is a retrospective analysis of firearm injuries and deaths in Qena Governorate which examined by medicolegal Department of Ministry of Justice in Qena during the years between January 2010 and December 2011.

This study demonstrate that the number of firearm injuries (fatal and nonfatal) was increased 
Qena during the year 2011 following the Egyptian revolution were firearm weapons were freely used due to absence of security role.

The present study illustrated that the highest percentage of age groups of was between 21-30 years represented $(31.25 \%)$ followed by the age group 31-40 years $(20.54 \%)$. The majority of victims were males (86.31\%).

Studies in other parts of the world revealed similar results as most victims were males in age group of 21-30 years like Sweden (Karlsson et al., 1993), Germany (Karger et al., 2002), Nigeria (Seleye-Fubara et al., 2009), Saudia Arabia (Al Madni et al., 2008), Iran (Amiri et al., 2003), India (Pradipkumar et al., 2005), Pakistan (Nasrullah and Razzak, 2009) and El Salvador (Paniagua et al., 2005).

In agreement with the present work was the study in Edirne, Turkey also reported that 54\% of firearm victims were aged between 20 and 40 years (Azmak et al., 1998). Also in Bari (Italy) most of victims in firearm fatalities were males which represented 93\% (Solarino et al., 2007). Similar results obtained in Faisalabad (India) where $28.19 \%$ of victims were in age groups $20-29$ and $77.66 \%$ victims were males (Bashir et al., 2007). Firearm related injuries in a Finland study during the years 1990-2003; revealed that men's injury incidence was 10 times that of women's and young men's aged 15-34 years displayed the highest incidence figures (Mattila et al., 2006). Firearm injuries are the highest of all categories of injuries between 15-34 years after which they equalize with stabbing injuries and the age group 20-24 years has the highest rate of nonfatal injuries from firearms in the capital of Honduras (Yacoub et al., 2006).

Comparable with results of the present work is the study of the pattern of firearm injuries and fatalities in Assiut Governorate, Egypt during the year 2006. The majority of victims were males which represented $86.31 \%$ of total cases and the peak age group was 20 30 years $(31.25 \%)$ then $31-40$ years $(20.25 \%)$ of total cases (Abdel Hady et al, 2008).

Also, in harmony with the present study in ElMenofia Governorate, Egypt during the year 2000. The maximum number of firearm injuries was in the age group 20-30 years. The majority of victims were males $88.6 \%$ of total cases which were near the figure in the present study $(86.31 \%)$. This might be due to the fact that males are more mobile, more violent and more liable to be engaged in quarrels and assault (Maklad et al., 2004).

The young age of most victims may be related to their unemployed status and might explain their willingness to engage in criminal activity. Also, young people are more aggressive by nature. Elderly people tend to act with restraint; their role is more to settle quarrels than provoking them. Youth pick up more fights and more involved as aggressors as well as victims. Males generally go for work outdoor and female tend to remain indoors. Males are also more exposed to daily stress activities. Males are also more affected than females as they are expected to have the moral prestige of the family and any threat to it can lead to violence (Kohli and Aggarwal, 2006; Solarino et al., 2007).

In the present work firearm injuries were common in summer and spring. The highest percentage of cases was in summer months which represented $30.3 \%$ and $33 \%$ of total cases respectively followed by spring months which represented $26.13 \%$ and $27.46 \%$ total cases in years 2010 and 2011 respectively. A similar results obtained in a study of firearm injuries in Suez canal area from year 2005 to year 2010 where the highest percentage of cases was in summer months which represented $53.7 \%$ of cases followed by spring months which represented $26.1 \%$ of total cases (Hagras et al., 2012). Disagreement with present work a study carried out to determine the prevalence of fatal and nonfatal firearm injuries in Alexandria, Egypt. The researchers reported that $31.5 \%$ of injuries occurred during autumn months, while the least occurred in summer months (20.4\%) (Abdel Salam et al., 2006).

In the current study the percentage of firearm injuries was $27.9 \%$ and $26.3 \%$ in urban area of Qena and Luxor cities in years 2010 and 2011 respectively while the percentage was $72.1 \%$ and $74.9 \%$ in rural areas of Qena Governorate in years 2010 and 2011 respectively. Similar finding was detected in the study of firearm injuries in El Fayoum Governorate in the period between years 2000 to 2007 . It was found that $73.2 \%$ of cases in rural area and $26.8 \%$ in urban area (Gamal Eldin et al., 2008).

In the present work most of inlet wounds were multiple which represented $57.6 \%$ and $66 \%$ of total in years 2010 and 2011 respectively. In agreement with the present work the study of fatal firearm injury in Bari (Italy) where multiple entrance wounds were more common than single entrance wounds (Solarino et al., 2007). Also the study of homicidal cases from firearm injury at autopsy in Adana, Turkey, it was found that multiple injury in $53.65 \%$ while the victims suffered a single wound in $47.35 \%$ of firearm-related murders (Hilal et al., 2005).

The results of the current study revealed that the highest percentage of injuries occurred from distant firing $84.5 \%$ and $97.5 \%$ of total cases respectively in 2010 and 2011 respectively. The majority of cases had multiple entrance wounds in $57.6 \%$ and $66 \%$ of total cases respectively. Also the majority of cases occurred by perpendicular firing $84.5 \%$ and $88 \%$ of total cases respectively. This is explained by homicidal injuries constituted the highest percentage of injuries.

In agreement, was a study of firearm injuries in Dammam, Saudi Arabia during the period from year 2002 to 2006 where distant range firing was observed in $65.6 \%$ of cases (Al Madni et al., 2008).

In the present study long rifled firearm weapons were the commonest type used which represented $87.4 \%$ and $96.4 \%$ of total in years 2010 
and 2011 respectively followed by short rifled weapons $11 \%$ and $2.7 \%$ of total in years 2010 and 2011 respectively, lastly non rifled $1.6 \%$ and $0.9 \%$ of total in years 2010 and 2011 respectively.

These results were in agreement with the study of homicidal firearm injuries in Sri Lanka during the period from June 2005 to July 2006, where long rifled weapons represented $98 \%$ of totally used weapons (Edirisinghe and Kitulwatte, 2010).

In contradiction with the present work is study of pattern of firearm injury in Assiut in the year 2006 by Abdel Hady et al. (2008) who reported that the long rifled weapons represented $21.43 \%$, short rifled constituted only $2.68 \%$. On the other hand homemade guns represented $75.89 \%$ of totally used weapons of them $55.65 \%$ fire shots and $20.24 \%$ fire bullets.

Homicide is one of the oldest crimes in human history. Motives of homicide include revenge, rage, jealousy, honor, dispute and argument/conflict (Drawdy and Myers, 2004 \& Hassan et al., 2005). Also drug abuse, drug trafficking and gang membership (Well et al., 2010). Cultural factors may contribute to such homicidal injuries such as poverty, unemployment, income inequality, defense of honor; alcohol consumption; methods of dispute resolution, weapon carrying and weaknesses in mechanisms of law enforcement (Seedat et al., 2009 and Shon, 2010).

In the current work the most common manner of injuries were homicidal injuries which represented $89.6 \%$ and $87.5 \%$, followed by accidental injury which represented $8.9 \%$ and $11.8 \%$ while fewer number were suicidal injury which represented $1.5 \%$ and $0.7 \%$ of total cases in 2010 and 2011 respectively.

Similar results obtained in a study of pattern of firearm injury in Assiut Governorate in year 2006 where homicidal manner represented $86.91 \%$. Accidental manner represented $12.20 \%$ and suicidal manner represented $0.89 \%$ of total cases (Abdel Hady et al., 2008).

Similar results were reported in the study of manner of firearm injuries in Menofia Governorate Egypt. It was found that the manner in $71.43 \%$ of the studied cases were homicidal, $28.57 \%$ were accidental and no suicidal or fabricated cases. These results can be explained as firearm is not the vulnerable method of suicide in Egypt (Maklad et al., 2004).

In Egypt some accidental firearm injury and deaths were reported in rural areas due to use of guns in wedding, holidays and festivals. Out of total of 29 years cases of firearm injuries admitted to Menoufiya University Hospitals, seven victims had no work which easily engaged in quarrels (Badawy et al., 2009).

Homicides predominantly occurred in young males residing in a rural locality. The peak incidence was between 20-29 years in males and in females the age group most prone was 30-39 years. Male to female ratio was $6: 1$. The chest $(33.8 \%)$ followed by the head and abdomen were the areas primarily targeted. High velocity automatic weapons are primarily being used to kill young people in rural areas. Prevention can be through strict gun control laws coupled with education and awareness (Marri and Bashir, 2010).

The fatal firearm cases due to rifled weapons examined at the Bexar County Medical Examiner's Office, USA between 1988 and 2004 were studied. A total of 509 cases were identified, with 233 suicides and 266 homicides, the head was the most common site of injury, homicides most often had multiple wound locations and sustained from a distant range (Molina and Di Maio, 2008).

Study of autopsies were conducted in DL Khan, Pakistan revealed that homicidal deaths constituted $259 / 341(76 \%)$ of all autopsies. Out of these homicides $59.07 \%$ were caused by the firearm. The most common firearm weapons were high velocity rifled weapons (AK-47, rifles and pistols). A total of 304 injuries were found in various body regions giving an average of about two injuries per victim/person. The head, neck and face sustained the highest numbers of injuries 100, (32.90\%) followed by chest 91 (29.93\%) and abdomen 47 (15.4\%); the extremities, buttock and genitalia together sustained 65 (21.38\%) injuries (Humayun et al., 2009). Also a study of fatal injuries in Campina Grande, PB, Brazil, between January 2003 and December 2007 reported that the head and face were found to be the commonest site of fatal firearm injuries

In agreement with the present work was the results of study of Berg et al., (2012) in the USA who mentioned that the extremities were the most commonly injured anatomic region in nonfatal firearm trauma and are associated with high rates of vascular, nerve and bony injury (Berg et al., 2012). Also a study of total of 286 patients with firearm injuries in Aga Khan University Hospital Karachi, Pakistan. Lower limb (30\%), abdomen (27\%) and pelvis were the most affected body regions. Most of injuries occurred during robbery (40\%) (Nasrullah and Razzak, 2009).

Study of homicidal firearm injuries in Sirlanka showed that the majority of victims $(\mathrm{N}=76)$ were young adult males (aged 18-40 years). Almost half of the firearm injuries were homicidal. Daylight hours (6.00 a.m. to 6.00 p.m.) were preferred by rebels, while there was no relation to the time of day in the other firearm deaths. The weapon of choice was a rifled firearm (98\%) (Edirisinghe and Kitulwatte, 2010).

Variation from common findings in death due to firearm injury is not commonly encountered. When there is an atypical finding, the forensic pathologist may feel difficulty to differentiate firearm entry wound from exit wound, tracing the wound track, estimating approximate range of firing and differentiating suicidal injury from homicidal injury. Failure to differentiate entry wound from exit wound can cause error in calculating number of projectiles entered into the body, lodged inside the body or exited through the body, besides posing problem in ascertaining direction of 
firing and direction of wound track. Failure to differentiate contact or close range firearm injury from distant range firearm injury can lead to wrong interpretation about the manner of death (Naik et al., 2011).

Study of fatal cases of firearm injury in Delhi, India, reported that $46.7 \%$ victims were aged between 20 and 30 years and $90.7 \%$ were males. $92.6 \%$ were victims of homicidal attacks, $6.5 \%$ suicidal and $0.9 \%$ accidental. Single firings were the norm. Chest (39\%) and head $(29.6 \%)$ were the two most common entry sites for the bullets (Kohli and Aggarwal, 2006). In the present work death occurred in $5.3 \%$ and $18.1 \%$ of total firearm injuries while nonfatal cases represented $94.7 \%$ and $81.9 \%$ of total in years 2010 and 2011 respectively. Permanent infirmities occurred in $6.7 \%$ and $7.1 \%$ of total cases $(7.1 \%$ and $8.7 \%$ of nonfatal cases) in years 2010 and 2011 respectively. It was found that the percentage of permanent infirmities was 8.9\% in firearm injuries in Assiut Governorate in 2006 (Abdel Hady et al., 2008) while the permanent infirmity represented $4.1 \%$ and cure with complications occurred in $2.1 \%$ of total cases in firearm injuries in Suez Canal area from year 2005 to year 2010 (Hagras et al., 2012).

Educational efforts and individual, community and societal approaches are needed to alleviate firearmrelated injuries (Nasrullah and Razzak, 2009). Stringent laws on illegal firearms handling should be enforced by the government to reduce the frequency of firearm death (Seleye-Fubara et al., 2009).

\section{Conclusions and recommendations}

The fatal and nonfatal firearm injuries in Qena Governorate were increased in year 2011 than year 2010 due to defect in police supervision in the community. Firearm injuries are still increasing which may be attributed to gun trafficking, easy access to firearm weapons, absence of law enforcement strategies, economic difficulties, low level of education and wrong social believes about revenge.

So minimization of firearm injuries in Qena Governorate necessitates activation of the police role, enforcement of law, prevention of use, possession and trafficking of unlicensed weapons by effective legislation. In addition strengthen the active role of conciliation and dispute resolution committees to solve problems of revenge and disputes among population belonging to different tribes in Qena Governorate. Also educational and social programs and solving the problem of unemployment are mandatory.

\section{References}

Abd El-Salam H, Darwish R, Madkour S and Abd ElWahab (2006): Retrospective and prospective study on the prevalence of fatal and nonfatal firearm injuries in Alexandria Egypt $J$ Forensic Sci Appl Toxicol, 6 (2): 107-127.
Abdel Hady RH, Abdel Moneim WM and Abdel Aal KM (2008): Firearm injuries and fatalities. A preliminary study report in Assiut Governorate, Egypt in year 2006. Zagazig J Forensic Med Toxicol, 6 (1): 97-118. H.

Al Madni O, Kharosha MA and Shotar AM (2008): Firearm fatalities in Dammam, Saudi Arabia. Med Sci Law. Jul; 48(3):237-40.

Amiri A, Sanaei-Zadeh H, Towfighi Zavarei H et al., (2003): Firearm fatalities. A preliminary study report from Iran J. Clin. Forensic Med., 10: 159-163.

Azmak D, Altun G, Bilgi S et al., (1998): Firearm fatalities in Edirne, 1984-1997. Forensic Sci. Int., 95 (3): 231-239.

Badway S, Hammad S and Girgis N (2009): Some medico-legal aspect of firearm injury cases admitted to Menoufiya University Hospitals over two years. Menoufiya Med. J; 22(1).

Bashir MZ, Saeed A, Khan D et al., (2007): Pattern of homicidal deaths in Faisalabad. J. Ayub Medical College,

Berg RJ, Okoye O, Inaba K et al., (2012): Extremity firearm trauma: the impact of injury pattern on clinical outcomes. Am Surg. Dec; 78(12):1383-7.

Braga AA, Wintemute GJ, Pierce GL et al. (2012): Interpreting the empirical evidence on illegal gun market dynamics. J Urban Health. Oct; 89(5):779-93.

Davies MJ, Wells C, Squires PA et al., (2012): Civilian firearm injury and death in England and Wales. Emerg Med J; 29:10-14.

Dingeldein L, Sheehan K, Krcmarik M et al., (2012): Evaluation of a firearm injury prevention web-based curriculum. Teach Learn Med.; 24(4):327-33.

Drawdy SM and Myers WC (2004): Homicide victim/offender relationship in Florida Medical Examiner District. J. Forensic Sci. Jan; 49(1):150-4.

Edirisinghe PA and Kitulwatte I G (2010): Homicidal firearm injuries: a study from Sri Lanka. Forensic Sci. Med. Pathol. Jun; 6(2):93-8.

Gamal Eldin A, El-Ghamry H, Ghalab S et al., (2008): Study of cases of firearms fatalities in ElFayoum Governorate during 7 years period (2000-2006) retrospective study. Beni Sueif Univ. Med. J; 1(1)70-72.

Hagras AM and Kharoshah MA (2012): Medicolegal evaluation of firearm injuries during the period from 2005 to 2010 in the Suez Canal area, Egypt: A retrospective e study. Egy. J. Forensic Sci., 2:1-10.

Hargarten S (2002): The physician's role in preventing small arms injury. Med Confl Surviv. OctDec; 18(4):389-93. 
Hassan Q, Shah MM and Bashir MZ (2005): Homicide in Abbottabad $\mathrm{J}$ Ayub. Med. Coll. Abbottabad. Jan-Mar; 17 (1):78-80.

Hilal A, Cekin N, Gülmen MK et al., (2005): Homicide in Adana, Turkey: a 5-year review. Am J Forensic Med Pathol. Jun; 26(2):141-5.

Humayun M, Khan D, Fasee-uz-Zaman et al., (2009): Analysis of homicidal deaths in district DI Khan: an autopsy study. J Ayub Med. Coll. Abbottabad. Jan-Mar; 21(1): 155-7.

Kapusta ND, Etzersdorfer E, Krall C et al., (2007): Firearm legislation reform in the European Union: impact on firearm availability, firearm suicide and homicide rates in Austria. Br J Psychiatry. Sep; 191:253-7.

Karger B, Billeb E and Koops E (2002): Accidental firearm fatalities. Forensic and preventive implications, Int. J. Legal Med. 116 (6): 350353.

Karlsson T, Isaksson B and Ormstad K (1993): Gunshot fatalities in Stockholm, Sweden with special reference to the use of illegal weapons, J. Forensic Sci. 38 (6): 1409-1421.

Kohli A and Aggarwal NK (2006): Firearm fatalities in Delhi, India. Leg Med (Tokyo). Oct; 8(5):2648.

Kunz SN, Brandtner H and Meyer H (2013): Unusual blood spatter patterns on the firearm and hand: A back spatter analysis to reconstruct the position and orientation of a firearm. Forensic Sci Int. May 10; 228(1-3):e54-7.

Leite Cavalcanti A, Barros De Alencar CY, Sant'Anna Araujo Rodrigues I et al., (2012): Injuries to the head and face in Brazilian adolescents and teenagers victims of non-natural deaths. J Forensic Odontostomatol. Jul.1; 30(1):13-21.

Maklad A, El- Mehy L and Mohdy M (2004): A medicolegal study of firearm injuries in ElMenofia Governorate. Ain Shams J. Forensic Med. Clin. Toxicol.; XIV:99-112.

Marri MZ and Bashir MZ (2010): An epidemiology of homicidal deaths due to rifled firearms in Peshawar Pakistan. J Coll. Physicians Surg. Pak.Feb; 20(2):87-9.

Mattila VM, Kakitie I and Pihlajamaki H (2006): Trends in hospitalization for firearm-related injury in Finland from 1990 to 2003, Trauma, Nov; 61 (5): 1222-27.

Molina DK and DiMaio VJ (2008): Rifle wounds: a review of range and location as pertaining to manner of death. Am. J. Forensic Med. Pathol. Sep; 29 (3): 201-5.

Naik SK, Kumar P, Atal DK et al., (2011): Multiple variations of firearm injuries - a case report. J Forensic Leg. Med. Oct; 18(7):325-8.

Narang P, Paladugu A, Manda SR et al., (2010): Do guns provide safety? At what cost? South Med. J. Feb; 103(2):151-3.
Nasrullah M and Razzak JA (2009): Firearm injuries presenting to a tertiary care hospital of Karachi, Pakistan. J. Inj. Violence Res. Jul; 1(1):27-31.

Paniagua I, Crespin E, Guardado A et al., (2005): Wounds caused by firearms in El Salvador, 2003-2004: epidemiological issues. Med. Confl. Surviv. Jul-Sep; 21(3):191-8.

Patowary AJ (2005): Study of pattern of injuries in homicidal firearm injury cases. J.Indian Accademy Forensic Med: 27 (2): 92-95.

Pradipkumar K, Marak FK, Supriya K et al., (2005): A Homicidal fatal firearm injuries. J. Indian Academy Forensic Med (JIAFM); 27(4): 22225.

Rana M, Warraich R, Rashad A, von See C et al., (2012): Management of comminuted but continuous mandible defects after gunshot injuries. Injury. Oct 18 . pii: S00201383(12)00429-9.

Richardson EG and Hemenway D (2011): Homicide, suicide and unintentional firearm fatality: comparing the United States with other highincome countries, 2003. J. Trauma. Jan; 70(1):238-43.

Seedat M, Van Niekerk A, Jewkes R et al., (2009): Violence and injuries in South Africa: prioritizing an agenda for prevention. Lancet. Sep 19; 374 (9694): 1011-22.

Seleye-Fubara D., Etebu, EN and Bob-Yellowe E (2009): Pathology of firearm mortalities in the Niger Delta region of Nigeria: a study of 136 consecutive autopsies. Med. Sci, Law; Jan; 49(1):51-5.

Shon PC (2010): Weapon usage in attempted and completed parricides in nineteenth-century America: an archival exploration of the physical strength hypothesis. J. Forensic Sci. Jan; 55(1): 232-6.

Solarino B, Nicoletti EM and Di Vella G (2007): Fatal firearm wounds: A retrospective study in Bari (Italy) between 1988 and 2003. Forensic Sci Int. May 24; 168(2-3):95-101.

Verzeletti A, Astorri P and De Ferrari F. (2009): Firearm-related deaths in Brescia (Northern Italy) between 1994 and 2006: a retrospective study. J Forensic Leg Med. Aug; 16(6):32531.

Wells W, Katz CM and Kim J (2010): Firearm possession among arrestees in Trinidad and Tobago. Inj. Prev. Oct; 16 (5): 337-42.

Yacoub S, Arellano S and Padgett-Moncada D (2006): Violence related injuries, deaths and disabilities in the capital of Honduras. Injury. May; 37(5):428-34. 
الملخص العربي

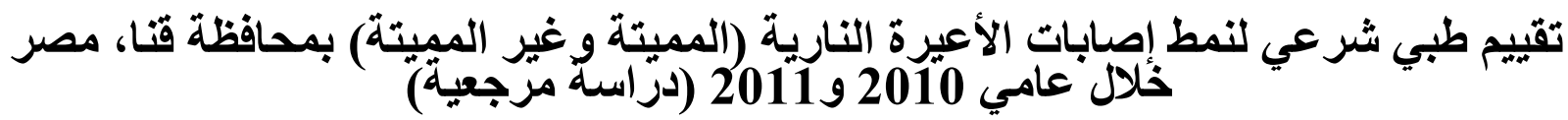

\author{
زغلول ثابت محمد و خالا محمد عبد العال 1 و إبراهيم نور محمد² و علي العبد حسن محمد3
}

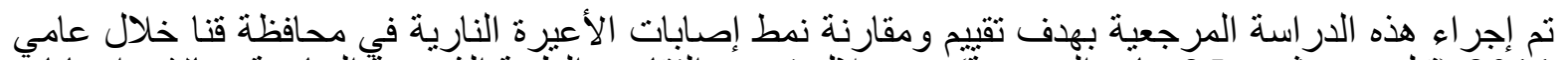

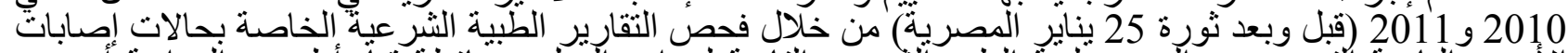

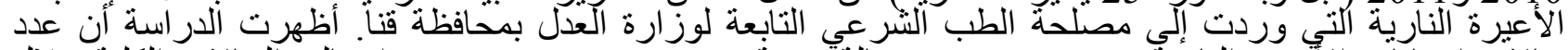

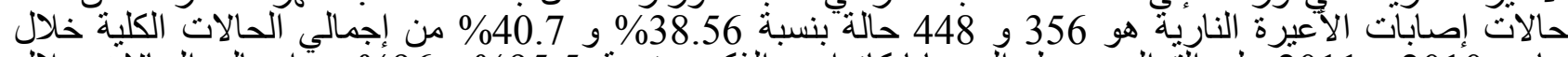

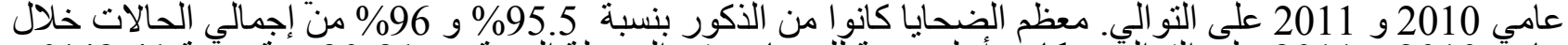

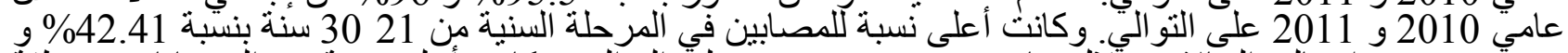

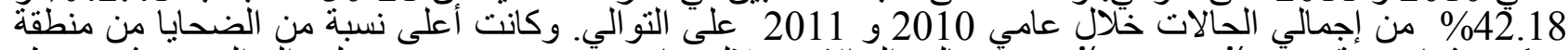

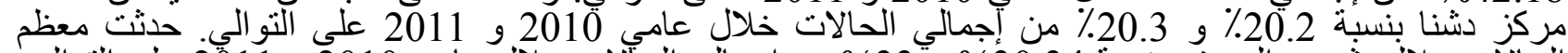

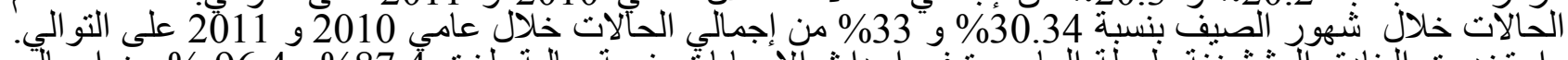

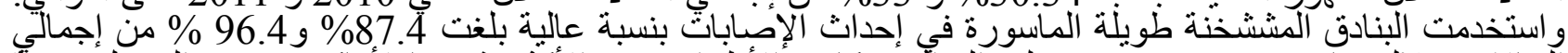

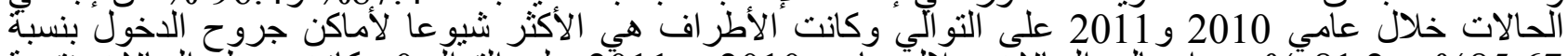

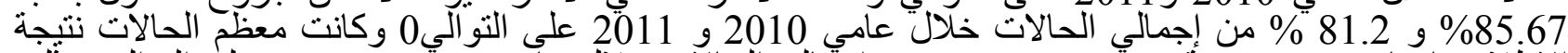

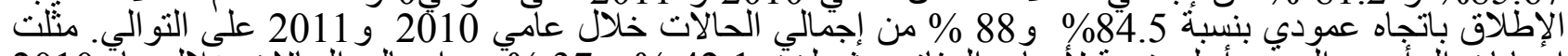

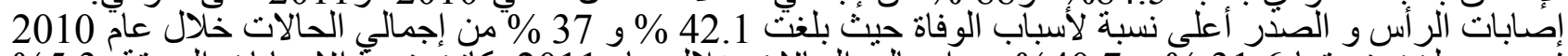

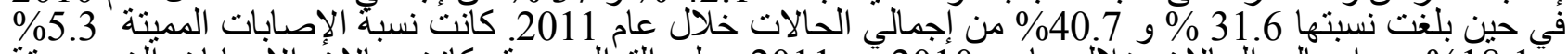

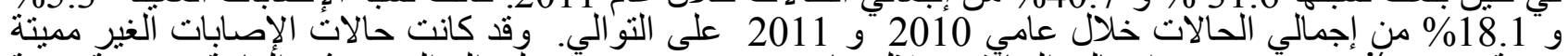

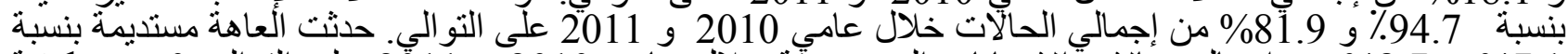

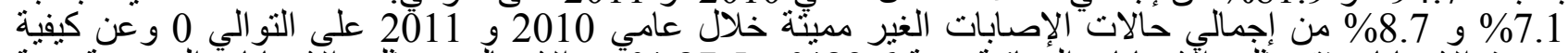

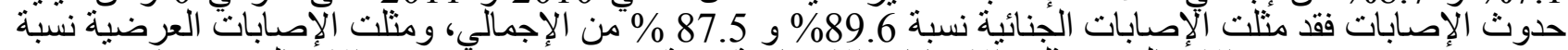

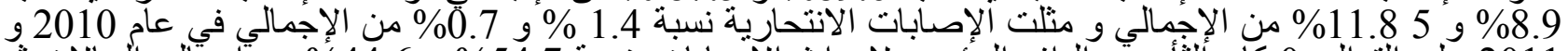

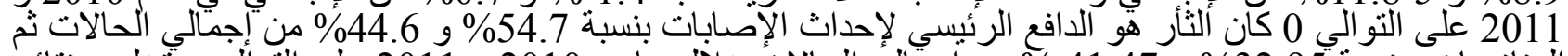

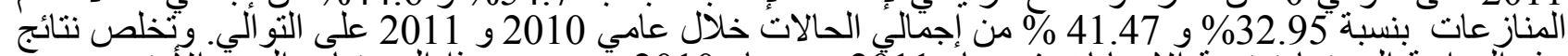

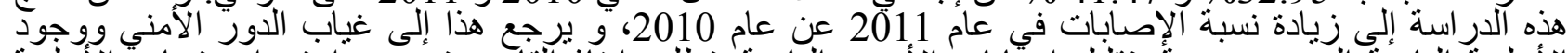

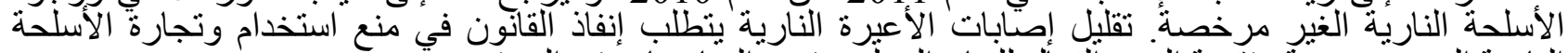

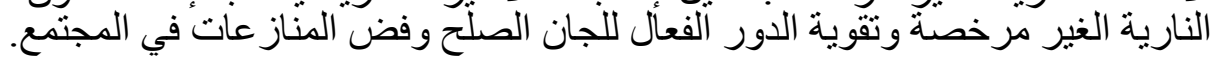

1 قسم الطب الشرعي و السموم الإكلينيكية كلية الطب جامعة أسيوط الطبية

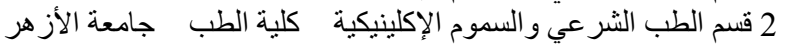

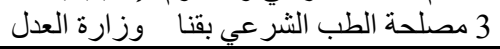

